\title{
Interdependence: A Concept Analysis
}

Chelsea Huth ${ }^{1}$, Beth Kelly ${ }^{2}$ and Sharon L. Van Sell ${ }^{3 *}$

${ }^{1}$ Graduate Nursing Program, Texas Woman's University, USA

${ }^{2}$ Graduate Nursing Program, Texas Woman's University, USA

${ }^{3}$ Professor, The Houston J. and Florence A. Doswell College of Nursing, Texas Woman's University, USA

\section{Abstract}

Interdependence has been defined as more than one entity working together to accomplish a common objective. The purpose of this concept analysis featuring interdependence was to dissect the meaning of the word and apply it to advance practice nursing, clinical practice, and research according to the Walker and Avant concept analysis methodology. The concept of interdependence was selected in order to display the working relationships in healthcare and show how each entity should work collectively to achieve a mutual aspiration.

\section{Introduction}

Interdependence has been described as more than one entity working together to accomplish a shared goal. The concept of interdependence was shown as a great importance in healthcare throughout this concept analysis. As a single unit, one person, or department, cannot solely provide complete and competent patient care. The healthcare system is composed of several departments and entities such as, but not limited to, the advance practice nurse, registered nurse, patient care technician, doctor, therapy, laboratory, pharmacy and even the patient. The concept of interdependence was selected in order to display the working relationships in healthcare and convey how each entity works harmoniously to achieve a common goal. Interdependence has been considered an important quality to advance practice nursing due to the constant contact with team members, such as the medical team, that require a mutual alliance and respect while working towards a combined purpose. Searle stated, "the nurse, whether as institutional practitioner or as a private contractor, is not the servant or subordinate of the doctor" (p. 20) [1] Searle underlined the importance of an interdependent relationship with physicians by highlighting the requirement of a partnership, rather than a dictatorship.

\section{Concept Analysis}

\section{Aim of the concept analysis}

According to Walker and Avant [2], the aim, or purpose, of a concept analysis "helps focus attention on exactly what use you intend to make of the results of your effort" (p. 161). The purpose of the concept analysis featuring interdependence was to examine the meaning of the word and apply it to advance practice nursing, clinical practice, and research. The concept analysis of interdependence described a crucial need for the nursing profession to correctly correlate multiple entities and define the mutual dependence on one another. The purpose of this interdependence concept analysis was to produce a definition and identify uses in the nursing profession.

\section{Relating theory to practice}

Interdependence has been known for relating theory to practice by describing reciprocated reliance between two individual entities. Several theories have adapted the concept of interdependence todescribe a mutual relationship. Balliet, Tybur, and Van Lange [3] tailored the interdependence theory to relate social interactions and their unique effects on behaviors that are applied in said interactions. Rodriguez, Neighbors, and Knee [4] used a model of interdependence to describe a relationship between marital distress and problematic alcohol use. Papadonikolaki, Vrijhoef, and Wamelink [5] described an interdependent relationship between a non-nursing topic of building information modeling technology and supply chain management. As shown, the concept of interdependence has been related to several different aspects in healthcare and other industries. Interdependence has been considered a valuable asset in connecting multiple elements and creating a discussion for the relationship of each subject.

\section{Definitions of interdependence}

The concept of interdependence has been described in a myriad of ways depending on the context used. Many practices of this concept were researched in different aspects, such as business, science, and nursing, to determine a clear viewpoint of the meaning and leave out any possible bias. "Interdependent was derived from the Latin word inter meaning among or between and dependere which means to hang from or be dependent on" (para. 2) [6]. Simply stated, interdependence involves dependence between things.

Interdependence has been defined in several ways. One definition was shown as "the quality or condition of being interdependent, or mutually reliant on each other" (para. 1) [7]. Which was also described as "a reciprocal relation between interdependent entities (objects or individuals or groups)" for example the relationship between plants and animals or the relationship of spouses in a marriage (para. 3) [8]. Per the business standpoint, it was stated that interdependence meant the "dependence of entities such as people or countries on each other, [for example] over the years, the United States' interdependence on other countries for imports has grown to record levels" (para. 1) [9].

"Corresponding Author: Prof. Sharon L. Van Sell, The Houston J. and Florence A. Doswell College of Nursing, 5500 Southwestern Medical Avenue, \#7209, Dallas, Texas, USA, 75235-7299, Tel: 1-864-275-3527, FAX: 214-689-6539; E-mail: svansell@twu.edu

Citation: Huth C, Kelly B, Van Sell SL (2017) Interdependence: A Concept Analysis. Int J Nurs Clin Pract 4: 225. doi: https://doi.org/10.15344/23944978/2017/225

Copyright: ( 2017 Huth et al. This is an open-access article distributed under the terms of the Creative Commons Attribution License, which permits unrestricted use, distribution, and reproduction in any medium, provided the original autho and source are credited. 
Even though each definition showed some variations, interdependence was related to "the dependence of two or more people or things on each other," whether involving living organisms, countries, or the effects human relationships have on one another (para. 1) [10]. No matter what circumstance, the "fact of depending on each other" described the main focus of the concept of interdependence (para. 1) [11].

\section{Attributes}

The attributes defined for the concept of interdependence were vital to this concept analysis. Walker and Avant [2] stated: "the cluster of attributes that are the most frequently associated with the concept and that allow the analyst the broadest insight into the concept" (p. 162). The attributes of a concept can function similar to differential diagnoses in medicine by aiding in identifying the concept when all attributes are present and differentiating a similar or related concept [2]. The attributes derived from a literature search and applied to the concept analysis of interdependence were described as follows: mutualism, team, alliance, and correlation.

According to the Merriam-Websterdictionary [12], mutualism was defined as "mutually beneficial association between different kinds of organisms" (para. 1). Mutualism was a key element in the interdependence concept analysis because it highlighted the importance that two or more different organisms/entities equally benefit from their relationship. The Merriam-Webster dictionary [13] defined team as "a group of people who work together" (para. 1) and "marked by devotion to teamwork rather than individual achievement" (para. 3). Being a member of a team was essential to the concept of interdependence because it emphasized the importance of working together to achieve a common goal.

The Merriam-Webster dictionary [14] listed the definition of alliance as "a relationship in which people agree to work together" (para. 1). The attribute of alliance was an important aspect of the concept of interdependence because it displayed the requirement of a joint agreement to complete a task. Correlation was defined by the Merriam-WebsterDictionary [15] as "a relation existing between phenomena or things or between mathematical or statistical variables which tend to vary, be associated, or occur together in a way not expected on the basis of chance alone" (para. 2). Correlationwas an asset to the concept of interdependence due to the relationship existing between two items that appear in accord.

Each attribute of interdependence added to the framework of this concept analysis. Mutualism, team, alliance and correlation helped express the need for a mutual relationship to efficiently accomplish a task together. In this concept analysis, the presence of mutualism, team, alliance and correlation were requiredin order for the concept of interdependence to be valid.

\section{Model case}

Walker and Avant [2] described a model case as "an example of the use of the concept that demonstrates all the defining attributes of the concept" (p. 163). The following describes an example of a model case that was createdin order to convey the concept of interdependence and its corresponding attributes.

Melanie, a 30-year-old registered nurse (RN), is currently working in the obstetrical labor and delivery unit of a hospital. She has been employed at this facility for five years, long enough to have gained a mutual respect for fellow physicians, coworkers, techs, and other members of the healthcare team. She has functioned as a staff nurse on the unit, as well as a charge nurse.

Melanie is worried because one of the staff nurses on the unit is taking care of a patient that is having a difficult labor. The patient is 39 weeks gestational age and has been undergoing an induction for the past 8 hours. She received an epidural for pain relief 4 hours ago. Despite efforts, the patient has remained $4 \mathrm{~cm}$ dilated and not progressing in labor and the fetal monitoring strip continues to have late decelerations. As a charge nurse, it is Melanie's job to address her concerns with the staff nurse who is assigned in taking care of the patient. The staff nurse agrees that despite valiant efforts of induction, frequent position changes, and fluid boluses, the fetal monitoring strip has not improved. Both Melanie and the staff nurse are in alliance that the physician should be notified and of the patient condition and recommend that the plan of care be changed, and a primary cesarean section should be considered.

The physician knows Melanie well and has created a great partnership with her based on previous experiences and agreed in the importance of Melanie and the staff nurse sharing the situation with him. He viewed the fetal monitoring strip from home and agrees to see the patient at the bedside and discuss a new plan of care. The anesthesiologist that placed the patient's epidural is notified of the situation and is on standby in case of the need for an operational delivery. The importance of a cesarean section is discussed with the patient with emphasis on the safety of both the mother and the baby. The patient agrees with this plan of care and is aware that the neonatal nurse practitioner, respiratory therapist, and NICU care team will be present at the delivery as well to better assess the infants extra uterine status.

Verbal standard orders for a cesarean section are initiated by the physician, Melanie is then able to put the orders in and create the case in the computer. The staff nurse gets the patient ready for the $\mathrm{C}$-section, the anesthesiologist sets up the operation room, the scrub tech prepares the instruments for delivery, and the NICU team sets up the infant warmer. The infant is delivered within the next 15 minutes with partial abruption noticed of the placenta. However, despite the decelerations, the infant is in stable condition. Mother and baby are both transferred to recovery without any complications.

This model case shows how collaboration of care is of great significance in the health care setting. All of the attributes of interdependence were displayed within this situation in relation to members of the healthcare team. One branch cannot work fully without the others. The patient depends on the nurses to take care of them, the nurses depend on the physicians create diagnoses and write orders, and the providers depend on the members of the care team to see that their orders are completed. Good teamwork between nursing and medical staff is important for improving patient safety, avoiding medical error and ensuring patient outcomes and staff wellbeing [16]. Each component of a health care team is mutually reliant on each other and share reciprocal relationships.

\section{Borderline case}

Walker and Avant [2] described a borderline case as "examples or instances that contain most of the defining attributes of the concept being examined but not all of them" (p.164). An example of a borderline case of the concept of interdependence was crafted and shown below. 
Sally is a newly graduated nurse practitioner working on a busy cardiac step down floor. Sally is a 29 -year-old married female with no children. Sally has been timid about the transition and has not found confidence in her new role. The senior internist on the unit, Dr. Arnold, has been assigned to precept her. Dr. Arnold is very knowledgeable, straightforward and firm in his teaching methods.

Sally has been very quiet and afraid to ask too many questions because her preceptor intimidates her. Dr. Arnold has underlined his importance of teamwork, alliance, partnership, correlation, and sharing. Although, Dr. Arnold has continually made comments degrading nurse practitioners and blaming the nurse practitioner for any mistakes made. This has made Sally uncomfortable because she feels as if Dr. Arnold does not treat her as an equal partner in patient care. Sally feels that the working relationship she shares with Dr. Arnold is unparalleled and does not possess mutualism.

This borderline case has shown the physician creating the environment of teamwork and a partnership between the physician and the nurse practitioner but not believing that the two are equal partners in developing patient care. Searle states the nurse practitioner is "not the servant or subordinate of the doctor. She is a registered nurse practitioner, entirely responsible and accountable for her own acts and omissions" (p. 20) [1]. The borderline case has been illustrated by possessing some of the attributes of the concept of interdependence but not all of the attributes.

\section{Contrary case}

According to Walker and Avant [2], "contrary cases are clear examples of "not the concept" and were described as cases that meet none of the attributes of the concept (p. 166). An example of a contrary case on the concept of interdependence was generated and depicted below.

A client proposes ideas to a project manager of an upcoming product that they would like to release. The project manager is in charge of deciding if the project can be completed and delegating tasks for team members. However, instead of allocating jobs to group members, the project manager tries to do all of the tasks by himself. This creates delays in the process. The project manager does not have the knowledge to complete each task and lacks the connections that the team members have to outside resources. In turn, the project does not get completed by the required deadline.

The project manager had no intention of getting other team members involved to finish the task. The desire was to work unaided coworkers. Interdependence positively relates to team performance [17]. Had the project manager collaborated with the members of his team, the client would have received the finished project on time. Also, the team members would have been able to get paid for working on the project, and the product would be available for the overall population to purchase.

\section{Antecedents and consequences}

Defining the antecedents and consequences was essential to help refine the attributes of the concept of interdependence. Walker and Avant [2] described antecedents as "events or incidents that must occur or be in place prior to the occurrence of the concept" (p. 167). Antecedents pertaining to the concept of interdependence were outlined as faith, acceptance, character, and circumstance. and individually, without interdependence or correlation with his

Faith has been defined as the "strong belief or trust in someone or something" (para. 1) [18]. Faith was shown as one of the most essential aspects of interdependence because faith and trust in others are key for relationships and dependence on other persons. Studies have shown that interpersonal context and team learning are significant in effective nursing team performance [17].

Acceptance of one another and understanding that systems must work together was conveyed as another essential antecedent of interdependence. Merriam-Webster Dictionary [19] defined acceptance as "agreeing either expressly or by conduct to the act or offer of another," which is key when working with others (para. 2). When using interdependence in the healthcare setting, one must decide if they are in agreement with the other team members. Acceptance of one another and collaboration of ideas has been shown to better outcomes of patient care. Studies also showed that interdependence with members of the healthcare team help develop nurse autonomy [20].

The next antecedent of interdependence was described as character. Characterwas shownin relation to the qualities that make up how someone thinks or feels [21]. Characteralso reflected a person's morals and belief systems. "Interdependence stimulates and challenges individual opinion, guides and augments initiative, and demands individual responsibility and accountability, attributes strongly associated with professional nurse autonomy," which pertained to character and belief in oneself (para. 13) [20]. Teamworkwas conveyed as being vitalfor systems to work interdependently based on faith and acceptance of the members' character and competence. Working together requires one to know the basis of the other members' beliefs so that they can trust them to make sound and competent decisions.

The last antecedent of interdependence noted in concept analysis was circumstance, or an event or situation. A setting was required as a basis for the need of collaborative care. Individual entities must have a common goal in order to work closely together. For example, doctors, nurse practitioners, therapists, etc., working as one team for the better outcome of patients in a hospital setting.

Consequences, on the other hand, are described by Walker and Avant [2] as "events or incidents that occur as a result of the occurrence of the concept - in other words, the outcomes of the concept" (p. 167). Several consequences of interdependence were identified in this concept analysis. These were acknowledged as less risk, knowledge, and transformation.

Interdependence has been known to create transformation, or change, which comes from a shared vision of a future [22]. Multiple parts of a care team come together to make the whole and create transformation in the healthcare setting and change for the patient. It has been said that "positive relationships between nurses and physicians [are] ones in which nurses are able consistently to exercise professional judgement with positive results on the quality and outcomes of patient care" (para. 28) [22]. Doctors, advanced practice nurses, lab technicians, pharmacy, registered nurses, and other members of the care team should develop an equilibrium when working together. Adopting a homeostatic approach is important for researchers and clinicians to plan comprehensive nursing care through interdependence [23].

\section{Empirical referents}

Walker and Avant [2] defined empirical referents as "classes or categories of actual phenomena that by their existence or presence 
demonstrate the occurrence of the concept itself" (p. 168). The final step in developing a concept analysis has been to express the empirical referents by asking a question of "if we are to measure this concept or determine its existence in the real world, how do we do so?" (p.168) [2]. The concept of interdependence has been perceived in the real world by the books and theories that have been written featuring the importance of interdependence. Bowlby, Mckie, Gregory, and Macpherson [24] have applied the concept of interdependence to their book titled Interdependency and Care Over the Life course. Kelly and Thibaut [25] have acknowledged the existence of interdependence in the real world by writing "Interpersonal Relations: A Theory of Interdependence."

As discussed earlier, several other scholars have adapted the concept of interdependence into their works. Balliet, Tybur, and Van Lange [3]authored "Functional Interdependence Theory: An Evolutionary Account of Social Situations." Rodriquez, Neighbors, and Knee [4] wrote "Problematic alcohol use and marital distress: An Interdependence Theory Perspective." Finally, Searle [1] scribed "The Dependent, Independent and Interdependent Functions of the Nurse Practitioner--A Legal and Ethical Perspective." The articles listed above have validated the concept of interdependence and related it to the real world.

\section{Impact on advanced nursing practice}

The concept of interdependence could have considerable influence on Advanced Practice Nurses (APNs). APNs have a great deal of autonomy with their patients. However, they still have to work under the practice of an MD. Therefore, a mutual dependence is placed on all members of the practice setting to work together, including doctors, APNs, registered nurses, lab technicians, etc. Interdependence can also impact the patients under the care of APNs because it gives the client a more well-rounded care team and, in turn, a better outcome. Working with team members is also mutually beneficial to each participant in the healthcare setting, especially to Advanced Practice Nurses, because it makes the APN more competent and resourceful in the care they provide.

\section{Impact on nursing research}

The concept of interdependence has had a great impact on present day use in nursing research by providing a conduit to relate two entities and describe a mutual dependence. The concept can be applied to a broad range of topics and individuals that wish to obtain a mutual functional affiliation. Interdependence has made an impact on nursing research because it sets a platform to find relationships between a wide range of subjects and it is easily applied to several different topics in the field of nursing.

\section{Discussion}

The interdependence concept map illustrated in figure 1has shown a working relationship involving all aspects of healthcare including the patient. The units highlighted in this map include the advance practice nurse, registered nurse, patient care technician, doctor, therapy, laboratory, pharmacy and the patient. This model has emphasized the importance of mutual dependence with each party involved in order to achieve interdependence. The collective individuals are required to work in unison to accomplish a common goal; in this case, the goal is efficient patient care. As discussed above, interdependence has been paramount in the healthcare environment because a single person cannot exclusively accomplish holistic and effective patient care. Rather, a skilled group of individuals mentioned above need to possess mutual alliance and trust in order to achieve success.

\section{Competing Interests}

The authors declares that the they have no competing interests.

\section{Funding}

This article was published with support from Texas Woman's University Libraries' Open Access Fund.

\section{References}

1. Searle $C$ (1982) The dependent, independent and interdependent functions of the nurse practitioner--a legal and ethical perspective. Curationis 5: 1923.

2. Walker LO, Avant KC (2011) Strategies for theory construction in nursing (5th edition). Upper Saddle River, NJ: Prentice Hall.

3. Balliet D, Tybur J, Van Lange $P$ (2016) Functional interdependence theory: An evolutionary account of social situations. Pers Soc Psychol Rev, [Epub ahead of print].

4. Rodriguez LM, Neighbors C, Knee CR (2014) Problematic alcohol use and marital distress: An interdependence theory perspective. Addiction Research \& Theory 22: 294-312.

5. Papadonikolaki E, Vrijhoef R, Wamelink H (2016) The interdependences of BIM and supply chain partnering: Empirical explorations. Architectural Engineering \& Design Management12: 476-494.

6. Interdependent (2016) In Vocabulary.com.

7. Interdependence (2016) In Dictionary.com.

8. Interdependence (2016) In Vocabulary.com.

9. Web Finance Inc (2016) In Businessdictionary.com

10. Oxford University Press (2016) In Oxforddictionaries.com

11. Cambridge University Press (2016) In Cambridge Academic Content Dictionary.

12. Mutualism (2016) In Merriam-Webster online dictionary.

13. Team (2016) In Merriam-Webster online dictionary.

14. Alliance (2016) In Merriam-Webster online dictionary.

15. Correlation (2016) In Merriam-Webster online dictionary.

16. Voyer B G, Reader T (2013) The self-construal of nurses and doctors: Beliefs on interdependence and independence in the care of older people. J Advd Nurs 69: 2696.

17. Ortega A, Sánchez-manzanares M, Gil F, Rico R (2013) Enhancing team learning in nursing teams through beliefs about interpersonal context. J Adv Nurs 69: 102-111.

18. Faith (2015) In Merriam-Webster online dictionary.

19. Acceptance (2016) In Merriam-Webster online dictionary.

20. Wade GH (1999) Professional nurse autonomy: Concept analysis and application to nursing education. J Adv Nurs 30: 310-318.

21. Character (2016) In Merriam-Webster online dictionary.

22. Mccormack B, Kitson A, Harvey G, Rycroft-malone J, Titchen A, et al. (2002) Getting evidence into practice: The meaning of 'context'. J Adv Nurs 38: 94-104.

23. Kim H, Rose KM (2014) Concept analysis of family homeostasis. J Adv Nurs 70: 2450-2468.

24. Bowlby S, Mckie L, Gregory S, Macpherson I (2010) Interdependency and Care over the Lifecourse, Routledge.

25. Kelley HH, Thibaut JW (1978) Interpersonal relations: A theory of interdependence (1st ed.). New York, NY: Wiley. 